\title{
Phenolic compounds and multivariate analysis of antiradical properties of red fruits
}

\author{
Anna Gramza-Michałowska ${ }^{1}$ (C) Marzena Bueschke ${ }^{1} \cdot$ Bartosz Kulczyński ${ }^{1} \cdot$ Anna Gliszczyńska-Świgło $^{2}$. \\ Dominik Kmiecik ${ }^{1} \cdot$ Agnieszka Bilska $^{1}$ - Małgorzata Purłan ${ }^{1} \cdot$ Lucyna Wałęsa $^{1} \cdot$ Michał Ostrowski $^{1}$. \\ Magdalena Filipczuk ${ }^{1} \cdot$ Anna Jędrusek-Golińska ${ }^{1}$
}

Received: 15 December 2018 / Accepted: 6 March 2019 / Published online: 12 March 2019

(c) The Author(s) 2019

\begin{abstract}
This paper presents a study on the antiradical properties of red fruits commonly consumed in Europe, i.e. strawberry (Fragaria ananasa), raspberry (Rubus ideaus), blackberry (Rubus fruticosus), cranberry (Vaccinium macrocarpon) and pomegranate (Punica granatum) extracts by various in vitro tests as well as the determination of qualitative and quantitative features of their phenolic compounds. Our results indicated richness of red fruits in phenolic compounds and variability of their chemical mixtures dominated generally by anthocyanins, ellagic acid and their derivatives. The selected fruit extracts exhibited notable antiradical activity by DPPH, ABTS, ORAC and PCL assays with significant correlation to phenolic content and remarkable influence of the chemical composition. This investigation indicated that the red fruits examined constitute prosperous natural sources of antiradical substances of high value which would benefit the product quality and consumers' health.
\end{abstract}

Keywords Strawberry $\cdot$ Raspberry $\cdot$ Blackberry $\cdot$ Cranberry $\cdot$ Pomegranate $\cdot$ Natural antioxidants

$\begin{array}{ll}\text { Abbreviations } \\ \text { GAE } & \text { Gallic acid equivalent } \\ \text { C3G } & \text { Cyanidin-3-glucoside } \\ \text { HPLC } & \text { High performance liquid chromatography } \\ \text { CYAD } & \text { Cyanidin derivatives } \\ \text { PELD } & \text { Pelargonidin derivatives } \\ \text { EAD } & \text { Ellagic acid derivatives } \\ \text { IQD } & \text { Isoquercitrin derivatives } \\ \text { TA } & \text { Total anthocyanins } \\ \text { SF } & \text { Flavonoids sum } \\ \text { TPC } & \text { Total phenolic compounds } \\ \text { VC } & \text { Vitamin C } \\ \text { PCL ACW } & \text { Photochem test water-soluble fraction } \\ \text { PCL ACL } & \text { Photochem test lipid-soluble fraction } \\ \text { PCL IAC } & \text { Photochem test integral antioxidant capacity } \\ \text { ABTS AE } & \text { Antiradical efficiency in ABTS test }\end{array}$

Anna Gramza-Michałowska

anna.gramza@up.poznan.pl

1 Faculty of Food Science and Nutrition, University of Life Sciences, Wojska Polskiego Str. 31, 60-624 Poznan, Poland

2 Faculty of Commodity Science, Poznań University of Economics and Business, Al. Niepodległości 10, 61-875 Poznan, Poland

\author{
DPPH AE Antiradical efficiency in DPPH test \\ ORAC Oxygen radical antioxidant capacity \\ FL Fluorescein \\ AA Antioxidant activity \\ TEC $_{50}$ The time needed to reach the steady state to \\ $\mathrm{EC}_{50}$ concentration.
}

\section{Introduction}

Oxidation causes changes in the nutritional value and organoleptic features of food, not only deteriorates the taste, aroma and color but it also decreases the nutritional value of food. In addition, toxic products are formed, including free radicals and their degradation products. The intensity of the process depends on the composition of fatty acids, storage conditions, and the presence of pro- and antioxidants [1]. The autoxidation process leads to the formation of free radicals and peroxides. There are also numerous short-chain compounds, including hydrocarbons, aldehydes, ketones, esters and alcohols, which are known as secondary products of lipid oxidation. Free radicals and their degradation products are harmful to health [2] by damaging cells and tissues, causing many diseases, and accelerating the aging process 
[2]. The negative effects can be prevented by antioxidants, which slow down the oxidation process. The food industry distinguishes two types of antioxidants: synthetic and natural [3]. Synthetic antioxidants are characterised by high efficiency and fast response. However, their use is limited due to inexplicable toxicity. Natural antioxidants in plants arouse great interest among scientists and consumers [4]. It is noteworthy that the addition of substances inhibiting oxidative processes and ensuring good quality of food is desirable both from the nutritional and technological point of view [5].

Antioxidants are compounds which reduce and block free radicals $[6,7]$. They form metal complexes that catalyze oxidation reactions, prevent reactions caused by single active oxygen, and inhibit the activity of oxidative enzymes, such as lipoxygenase. The effectiveness of antioxidants in plant products also depends on their adequate concentration. The set optimum limit has antioxidative effect on the product, while other concentrations may have pro-oxidative effect. When using antioxidants in the food industry it is necessary to pay attention to their behaviour. Some of them may exhibit antioxidative effects during storage, but they may lose their activity at high temperature, and vice versa. Numerous studies support the use of polyphenols to inhibit oxidative processes and prolong the shelf life of products. Polyphenols can mostly be found in fruit and vegetables. Locally grown seasonal fruits such as strawberries, raspberries, blackberries, cranberries and pomegranates are particularly important sources of antioxidants in Europe. Recently there has been increased interest in the influence of fruit and vegetable consumption on health $[4,8,9]$. It may be caused by the fact that, as scientists point out, fruits are a good source of natural antioxidants, e.g. in the form of phenolic compounds, which are better accepted than synthetic antioxidants commonly used in the industry [10]. Therefore, the aim of this paper was to compare the effectiveness of widely consumed red fruits in Europe as a source of antioxidant substances by determination of the quantitative and qualitative phenolic features as well as the evaluation of their antiradical potencies by using divers agreed assays.

\section{Materials and methods}

\section{Chemicals and reagents}

DPPH (2,2-diphenyl-1-picrylhydrazyl), Trolox (6-hydroxy2,5,7,8-tetramethylchroman-2-carboxylic acid), ABTS (2,2'-azinobis [3-ethylbenzothiazoline-6-sulfonic acid]), AAPH (2,2'-azobis(2-methylpropionamide)-dihydrochloride) (Sigma-Aldrich, Germany); Folin Ciocalteu Ragent, fluorescein disodium (Fluka, Germany); ACW kit-Antioxidant Capacity of Water-soluble substances and ACL
kit-Antioxidant Capacity of Lipid-soluble substances (Analytik Jena AG, Germany); sodium carbonate (POCh, Poland); purified water (Arium Sartorius, Germany); HPLCgrade acetonitrile, methanol and ethanol (Merck, Germany); cyanidin-3-glucoside (Roth, Germany); gallic acid (Sigma, Germany); standards of pelargonidin 3-glucoside, pelargonidin 3,5-diglucoside, cyanidin 3-glucoside, cyanidin 3,5-diglucoside, cyanidin 3-galactoside, quercetin 3-glucoside (Extrasynthèse, France); ellagic acid (Sigma-Aldrich, Germany). All of other purchased reagents used were of analytical grade.

\section{Plant material and extract preparation}

Strawberry (Fragaria ananasa var. Elsanta), raspberry (Rubus ideaus L. var. Polana), blackberry (Rubus fruticosus var. Polar), cranberry (Vaccinium macrocarpon var. Pilgrim) and pomegranate (Punica granatum L. var. Mollar de Elche) were freshly collected from local cultivations of Wielkopolska in Poland (strawberry, raspberry, blackberry), British Columbia in Canada (cranberry) and Alicante in Spain (pomegranate). All fruits were collected in a mature stage for consumption. Fruits were washed, peduncles were removed, pomegranate was peeled. Extraction procedure was conducted according to Kmiecik et al. [11]. Briefly, $100 \mathrm{~g}$ of fruit was homogenized, freeze dried and macerated at optimized conditions $\left(250 \mathrm{ml} 80 \%\right.$ ethanol, $21{ }^{\circ} \mathrm{C}$, sequential mixing). After $24 \mathrm{~h}$, the extracts were collected (the process was repeated three times). The supernatant was filtered, centrifuged ( $3000 \mathrm{rpm}, 6 \mathrm{~min}$ ), and then evaporated on vacuum rotary evaporator $\left(45^{\circ} \mathrm{C}\right)$, the residue was freeze dried and final extracts were stored frozen $\left(-18{ }^{\circ} \mathrm{C}\right)$. The rate of production yield was 3.6, 6.1, 6.7, 7.1 and 5.2 (\% of dry weight) for strawberry, raspberry, blackberry, cranberry and pomegranate respectively. The crude extracts were dissolved freshly in $80 \%$ ethanol prior further analysis. Fruit extracts applied for the research were: 100-2000 ppm.

\section{HPLC determination of phenolic compounds}

The phenolic compounds of fruit extracts were identified and quantified by using high performance liquid chromatography (HPLC) performed on Waters (Milford, MA, USA) model 600 HPLC system with photodiode-array 996 detector. Polyphenols in the fruit extracts were separated on the LiChrospher C18 column $\left(3.9 \times 250 \mathrm{~mm}^{2}, 5 \mu \mathrm{m}\right.$, Merck, Darmstadt, Germany). A gradient of mobile phase consisting of acetonitrile (A) and 5\% formic acid (B) was developed and used according to the following program: $10 \% \mathrm{~A}$ for $5 \mathrm{~min}$ and a linear increment to $30 \% \mathrm{~A}$ in next $15 \mathrm{~min}$. The column was rinsed by a linear increment to $100 \%$ A within 1 min, which was kept for next $4 \mathrm{~min}$. The re-equilibration of column was done by a linear decrease to $10 \%$ A within 1 min, which was kept for an 
additional $10 \mathrm{~min}$. Solvent flow rate was $1 \mathrm{~mL} / \mathrm{min}$ and the volume of the injected sample was $20 \mu \mathrm{L}$. Identification of compounds was performed by comparing their retention times with retention times of the standard used as external and/or internal standards. Additionally, the presence of polyphenols in the extracts was confirmed by the absorption spectra obtained by the photodiode-array detector application. The content of the individual compounds in the extracts was determined based on calibration curves prepared at least twice for each compound under the same chromatographic conditions as those used for the separation of the polyphenol compounds in the extracts. Unidentified flavonoids were determined based on the standard curve of the flavonoid which absorption spectrum was most similar to that of the unknown compound. The presence of the corresponding flavonoid glycosides was also confirmed by the disappearance after the extract acid hydrolysis. Results were expressed as $\mu \mathrm{g} / \mathrm{g}$ of the extract.

\section{Determination of total phenolic compound}

The method described by Kmiecik et al. [11] was used for determination of total phenolic compounds in the fruit extracts. Briefly an aliquot $(10 \mathrm{~mL})$ of the extract sample $(0.1 \mathrm{mg} / \mathrm{mL}), 2.5 \mathrm{~mL}$ of Folin-Ciocalteu phenol reagent and $5 \mathrm{~mL}$ of $20 \%$ solution of sodium carbonate were mixed, and the volume was than made up for $50 \mathrm{~mL}$. The $60 \mathrm{~min}$ incubation was followed by the absorbance measurement $\lambda=750 \mathrm{~nm}$. Results were expressed as $\mathrm{mg}$ gallic acid equivalents (GAE)/g extract, using the calibration curve over the range of $0-600 \mathrm{mg} / \mathrm{mL}\left(\mathrm{y}=2.0180 \mathrm{x}+0.0028, \mathrm{R}^{2}=0.9984\right)$.

\section{Total anthocyanins content}

Determination of total anthocyanins content was described by Oszmiański [12]. The dye was dissolved in acetate buffer at $\mathrm{pH} 1$ and after $120 \mathrm{~min}$ the absorbance was measured at $\lambda=510 \mathrm{~nm}$. The total anthocyanin content was calculated from the calibration curve prepared for the standard cyanidin-3-glucoside (Roth) under the same conditions. Results are presented as mg cyanidin-3-glucoside/g extract.

\section{Vitamin C content}

The content of vitamin $\mathrm{C}$ was evaluated spectrophotometrically according to method PN-A-04019 [13]. Results are presented as $\mathrm{mg}$ vitamin $\mathrm{C} / 100 \mathrm{~g}$ extract.

\section{Antiradical activity}

\section{DPPH radical scavenging activity}

The antiradical activity of fruit extracts against DPPH radical was assessed using method described by
Sánchez-Moreno et al. [14]. Briefly, an aliquot $(0.1 \mathrm{~mL})$ of extract methanol solution $(0.1-2 \mathrm{mg} / \mathrm{mL})$ was added to $3.9 \mathrm{~mL}$ of DPPH $(0.025 \mathrm{~g} / \mathrm{L}$ prepared daily). Then the absorbance at $\lambda=515 \mathrm{~nm}$ was measured at different time intervals until the reaction reached a plateau. The standard curve for Trolox was used for the calculation of antioxidant activity AA $\left(\mathrm{y}=548.12 \mathrm{x}-1.0125, \mathrm{R}^{2}=0.9819\right)$ and the result is expressed as mg Trolox equivalents/g extract. The percentage of remaining DPPH radical was plotted to obtain the amount of antioxidant necessary to decrease the initial radical concentration by $50 \%$. $\mathrm{T}_{\mathrm{EC} 50}$ - the time needed to reach the steady state to $\mathrm{EC}_{50}$ concentration was calculated graphically. Efficiency of antiradical activity (AE) calculated as following: $\mathrm{AE}=1 / \mathrm{EC}_{50} \times \mathrm{T}_{\mathrm{EC} 50}$. Where $\mathrm{T}_{\mathrm{EC} 50}$ is the time needed to reach the steady state of $\mathrm{EC}_{50}$ concentration that was calculated graphically.

\section{ABTS cation-radical scavenging activity}

The antiradical activity of fruit extracts against ABTS cation-radical was assessed using method described by Re et al. [15]. Briefly, ABTS solution ( $3 \mathrm{~mL})$ was added to 30 $\mu \mathrm{L}$ of extract sample $(0.1-2.0 \mathrm{mg} / \mathrm{mL})$, then the absorbance at $\lambda=734 \mathrm{~nm}$ was measured at different time intervals until the reaction reached a plateau. The standard curve for Trolox was used for the calculation of antioxidant activity AA $\left(y=87.219 x+0.2124, R^{2}=0.9838\right)$ and the result are expressed as $\mathrm{mg}$ Trolox equivalents/g extract. AE parameter for ABTS assay was calculated using the same equation as in DPPH method [16].

\section{PCL}

Analysis were conducted on Photochem ${ }^{\circledR}$ apparatus based on methodology published by Gramza-Michałowska et al. [17]. Determination of antiradical activity with the PCL assay is based on the detection of superoxide anion radicals $\left(\mathrm{O}_{2}{ }^{-}\right)$generated upon exposure to light and the presence of a photosensitizer, chemiluminogenous compound-luminol (5-amino-2,3-dihydro-1,4-phthalazinedione). PCL evaluations are presented as antioxidant activity of both lipid-soluble (ACL) and water-soluble (ACW) fractions due to kits and protocol provided by the manufacturer (Analytik Jena, Germany). Results were expressed as integral antioxidant capacity (IAC) in $\mu \mathrm{mol}$ Trolox equivalents/mg extract.

\section{ORAC}

Oxygen Radical Absorbance Capacity Assay $\left(\mathrm{ORAC}_{\mathrm{FL}}\right)$ was assayed using a method described by Gramza-Michałowska et al. [18], which is based on the antioxidant ability to scavenge peroxyl radicals using fluorescein solution (FL). Readings were taken at a given excitation $(\lambda=493 \mathrm{~nm})$ and 
emission wavelength $(\lambda=515 \mathrm{~nm})$ on a fluorescence spectrophotometer (Hitachi F-2700). Results were expressed as $\mu \mathrm{mol}$ of Trolox equivalents /g extract.

\section{Statistical analysis}

Results represent the means of three independent experiments (means $\pm \mathrm{SD}, \mathrm{n}=3$ ). Data were analysed using ANOVA one-way analysis of variance, differences were considered statistically significant at $\mathrm{P}<0.05$. Principal component analyses (PCA) of the significant antioxidant activity of the extracts were implemented by using a correlation matrix. Statistica 12.0 software (StatSoft) was used for the analysis.

\section{Results and discussion}

\section{Chemical composition}

Five types of fruits were selected for the research: strawberry (Fragaria ananasa), raspberry (Rubus ideaus), blackberry (Rubus fruticosus), cranberry (Vaccinium macrocarpon) and pomegranate (Punica granatum). The total polyphenol, anthocyanin and vitamin $\mathrm{C}$ contents are shown in Table 1. The HPLC analysis indicated that the ethanolic extracts of fruits contained polyphenolic compounds. These were mainly anthocyanins, ellagic acid and its derivatives. The content of polyphenols in raspberries was significantly greater $(\mathrm{P}<0.05)$ than in blackberries, strawberries and pomegranates. The content of total flavonoids in cranberries was about 103 times lower than in raspberries and about 64 times lower than in blackberries. The polyphenol content in the strawberry fruit extract measured by means of HPLC included the dominant compounds, i.e. pelargonidin 3-glucoside, quercetin 3 -glucoside and ellagic acid. There were also unidentified anthocyanins and flavonoids, which probably belonged to flavonol glycosides. Pelargonidin 3,5-diglucoside was the dominant compound in the raspberry extract, as its content amounted to over $90 \%$. However, it was absent in all other fruit extracts. In addition to this compound, cyanidin 3-glucoside, isoquercitrin and ellagic acid were found. Quercetin 3-glucoside and pelargonidin 3-glucoside were the predominant compounds in the cranberry extract. There were also two unidentified anthocyanins and flavonoid, which probably belonged to flavonol glycosides. Cyanidin 3-glucoside was the main compound identified in the blackberry extract, as its content amounted to more than $70 \%$. Ellagic acid and unidentified anthocyanins were also found. Their total content expressed as cyanidin 3-glucoside equivalents was $1863 \mu \mathrm{g} / \mathrm{g}$. The pomegranate bunch extract contained ellagic acid and its derivatives, which amounted to about $97 \%$ of all compounds. There were also other compounds, i.e. cyanidin 3,5-diglucoside, cyanidin 3-glucoside and pelargonidin 3-glucoside. The fruit extracts ranked in descending order $(\mathrm{P}<0.05)$ according

Table 1 Phenolic profile, total phenolic compounds, anthocyanins and vitamin C content in fruit extracts

\begin{tabular}{|c|c|c|c|c|c|}
\hline \multirow[t]{2}{*}{ Compound } & \multicolumn{5}{|l|}{ Extract } \\
\hline & Strawberry & Raspberry & Cranberry & Blackberry & Pomegranate \\
\hline Pelargonidin 3-glucoside ( $\mu \mathrm{g} / \mathrm{g} \mathrm{dw})$ & $1439^{\mathrm{d}} \pm 24$ & $55^{\mathrm{c}} \pm 6$ & $29^{\mathrm{b}} \pm 1$ & nd & $4.1^{\mathrm{a}} \pm 0.5$ \\
\hline Pelargonidin 3,5-diglucoside ( $\mu \mathrm{g} / \mathrm{g} \mathrm{dw})$ & nd & $12,880 \pm 110$ & nd & nd & nd \\
\hline Cyanidin 3-glucoside ( $\mu \mathrm{g} / \mathrm{g} \mathrm{dw})$ & $10.7^{\mathrm{a}} \pm 0.5$ & $783^{b} \pm 1$ & nd & $6455^{c} \pm 385$ & $13.1^{\mathrm{a}} \pm 0.8$ \\
\hline Cyanidin 3,5-diglucoside ( $\mu \mathrm{g} / \mathrm{g} \mathrm{dw})$ & nd & nd & nd & nd & $30.9 \pm 0.4$ \\
\hline Cyanidin 3-galactoside ( $\mu \mathrm{g} / \mathrm{g} \mathrm{dw})$ & nd & nd & $14 \pm 1$ & nd & nd \\
\hline $\begin{array}{l}\text { Unknown anthocyanins (quantified as cyanidin 3-glucoside) } \\
(\mu \mathrm{g} / \mathrm{g} \mathrm{dw})\end{array}$ & nd & nd & $18^{\mathrm{a}} \pm 1$ & $1863^{\mathrm{b}} \pm 27$ & nd \\
\hline $\begin{array}{l}\text { Unknown anthocyanin (quantified as pelargonidin 3-glucoside) } \\
\text { (ug/g dw) }\end{array}$ & $178^{\mathrm{b}} \pm 4$ & nd & $9.0^{\mathrm{a}} \pm 0.4$ & nd & nd \\
\hline Quercetin 3-glucoside (isoquercitrin) ( $\mu \mathrm{g} / \mathrm{g} \mathrm{dw})$ & $530^{c} \pm 13$ & $140^{\mathrm{b}} \pm 6$ & $45^{\mathrm{a}} \pm 1$ & nd & nd \\
\hline Unknown flavonoid glycosides (quantified as isoquercitrin) ( $\mu \mathrm{g} / \mathrm{g} \mathrm{dw})$ & $385^{\mathrm{c}} \pm 5$ & $53^{\mathrm{b}} \pm 2$ & $22^{\mathrm{a}} \pm 1$ & nd & nd \\
\hline Ellagic acid $(\mu \mathrm{g} / \mathrm{g} \mathrm{dw})$ & $680^{\mathrm{c}} \pm 17$ & $140^{\mathrm{a}} \pm 6$ & nd & $418^{\mathrm{b}} \pm 22$ & $878^{\mathrm{d}} \pm 13$ \\
\hline Ellagic acid derivatives (quantified as ellagic acid) $(\mu \mathrm{g} / \mathrm{g} \mathrm{dw})$ & $93^{b} \pm 2$ & $50^{\mathrm{a}} \pm 1$ & nd & nd & $1107^{\mathrm{c}} \pm 25$ \\
\hline Sum of flavonoids $(\mu \mathrm{g} / \mathrm{g} \mathrm{dw})$ & $3315^{\mathrm{c}} \pm 9$ & $14,101^{\mathrm{e}} \pm 19$ & $137^{\mathrm{a}} \pm 1$ & $8735^{\mathrm{d}} \pm 87$ & $2033^{\mathrm{b}} \pm 8$ \\
\hline Total phenolic compounds (mg GAE/g dw) & $30.86^{\mathrm{b}} \pm 0.38$ & $36.64^{\mathrm{c}} \pm 0.80$ & $23.56^{\mathrm{a}} \pm 2.99$ & $27.02^{\mathrm{a}} \pm 2.23$ & $24.41^{\mathrm{a}} \pm 0.76$ \\
\hline Total anthocyanins (mg C3G/g dw) & $7.54^{\mathrm{c}} \pm 0.08$ & $4.78^{\mathrm{b}} \pm 0.09$ & $0.37^{\mathrm{a}} \pm 0.11$ & $9.31^{\mathrm{d}} \pm 0.04$ & $9.61^{\mathrm{d}} \pm 0.81$ \\
\hline Vitamin C (mg/100 g dw) & $0.09^{\mathrm{a}} \pm 0.01$ & $0.11^{\mathrm{a}} \pm 0.01$ & $0.08^{\mathrm{a}} \pm 0.00$ & $0.06^{\mathrm{a}} \pm 0.00$ & $59.8^{\mathrm{b}} \pm 84.6$ \\
\hline
\end{tabular}

Values are means of three determinations \pm SD. Means in a row followed by the same small letter are not significantly different $(\mathrm{P}<0.05)$

$G A E$ gallic acid equivalent, $C 3 G$ cyanidin-3-glucoside, $n d$ not detected 
to the content of flavonoids as follow: raspberry $>$ blackberry $>$ strawberry $>$ pomegranate $>$ cranberry.

The total phenolic content (TPC) was measured by means of the non-specific Folin-Ciocalteau assay, which is easy to implement and frequently used even though it provides information on the chemical reducing capacity of the tested sample relative to an equivalent reducing capacity of gallic acid. As expected, the measurements of the TPC in the selected fruits showed that raspberry extract had the highest phenolic content. There were much lower amounts (about 22\%) in strawberry, cranberry, blackberry and pomegranate extracts (Table 1). Spectrophotometric measurements of total anthocyanins showed the highest content in blackberry and pomegranate extracts, which were $96 \%$ greater than in cranberry extract. The highest content of vitamin $\mathrm{C}$ was found in pomegranate extract $(59.8 \mathrm{mg} / 100 \mathrm{~g})$. There were 600 times lower amounts of this component in the other extracts (Table 1).

Ljevar et al. [19] analysed the content of polyphenols and total anthocyanins in selected fruit wines. The highest contents were observed in wines produced from cherries $(2074.9 \mathrm{mg} / \mathrm{L})$, blackcurrants $(2013.6 \mathrm{mg} / \mathrm{L})$, bilberries (1936.3 mg/L) and raspberries (1599.7 mg/L), whereas the lowest amounts were obtained with strawberry $(752.0 \mathrm{mg} / \mathrm{L})$ and apple wine $(449.7 \mathrm{mg} / \mathrm{L})$. The phenolic composition of these wines showed superiority of blueberry in phenolic acids such as gallic, protocatechuic and p-coumaric acids, whereas raspberry wine reveals the highest concentrations of $(+)$-catechin $(11.06 \mathrm{mg} / \mathrm{L})$, $(-)$-epicatechin $(32.13 \mathrm{mg} / \mathrm{L})$, and quercetin $(4.51 \mathrm{mg} / \mathrm{L})$. On the other hand, blackcurrants and cherries appeared as the richest sources of anthocyanins. The qualitative features of these bioactive components share numerous common components including delphinidin-3-rutinoside, delphinidin-3-glucoside, cyanidin-3-sophoroside, cyanidin-3-glucosylrutinoside, cyanidin-3-glucoside, cyanidin3-rutinoside in all fruits except for strawberries and apples.

Huang et al. [20] analysed the concentrations of polyphenols, flavonoids and anthocyanidins in blackberries, blueberries and strawberries. Blackberries had the highest content of polyphenols $(9.44 \mathrm{mg} / \mathrm{g})$, flavonoids $(36.08 \mathrm{mg} / \mathrm{g})$ and anthocyanidins $(24.38 \mathrm{mg} / \mathrm{g})$. The lowest amount of these compounds was found in strawberries. The chemical profiling of blueberries revealed presence of $p$-hydroxybenzoic and vanillic acids, as well as anthocyanidins, dominated by malvidin-3-galactoside and malvidin-3-glucoside, and minor concentrations of catechins, caffeic acid, ferulic acid, rutin, mirycetin, quercetin and quercitrin. Blackberries and strawberries were characterized by gallocatechin, epigallocatechin, catechin, quercitrin, luteolin, malvidin-3-glucoside and phenolic acids (caffeic, $p$-coumaric, procatechic, hydroxybenzoic, and ellagic acids) as common phenolics.
Phenolic compounds are among the bioactive mixture of pomegranates and cranberry. The phenolic content of pomegranates varies depending on the cultivar between 203.2 and $272.1 \mathrm{mg} / \mathrm{g}$ [21]. Previous published papers have been indicated that gallic acid, ellagic acid, 2-O-galloyl punicalagin, punicalagin $\mathrm{A}$ and $\mathrm{B}$, punicalin $\mathrm{A}$ and $\mathrm{B}$, granatin $\mathrm{A}$ and $\mathrm{B}$ are the common polyphenols found in pomegranate juices and extracts [21-23]. Furthermore, the phenolic profile of cranberry was checked. The study of Grace et al. [24] reported anthocyanins (mainly peonidin-galactoside, peonidin-arabinoside, cyanidin-arabinoside, and cyanidingalactoside) and proanthocyanidins accompanied by minor quantities of cyanidin-glucoside and peonidin-glucoside in fresh cranberries. Another study by Cásedas et al. [25] resulted in the identification of cyanidin-3-O-glucoside, cyanidin-3-O-arabinoside, peoinidin 3-O-glucoside, and peonidin 3-O-arabinoside in cranberry juice. Additionally, strawberries, raspberries, cranberries, blackberries and pomegranates were reported also as very important sources of vitamin C. Hakkinen et al. [26] found high content of this vitamin in strawberries $(47.8 \mathrm{mg} / 100 \mathrm{~g})$ and cranberries $(20.0 \mathrm{mg} / 100 \mathrm{~g})$. The amounts recorded in blackberries [27] and raspberries [28] ranging from 10.28 to $25.39 \mathrm{mg} / 100 \mathrm{~g}$ and 21 to $36 \mathrm{mg} / 100 \mathrm{~g}$, respectively, were lower than data reported for pomegranate juice reaching $58 \mathrm{mg}$ of vitamin $\mathrm{C} / 100 \mathrm{~g}$ [29].

Our findings were congruent with above mentioned investigations in terms of richness of red fruits in bioactive constituents, and reveal that their contents are quite variable. The concentration of phenolic compounds and their derivatives in fruits and other anatomical parts of plants can be influenced by the species and several other factors, which may cause notable variations even within the same species [30-32]. For example, the biosynthesis of anthocyanins is significantly influenced by sunrays; this interaction may be manifested by more intense colour of fruit on the sunny side [12]. In another study, Gündüz and Ozdemir [31] proved the importance of genetic background for the antioxidative capacity and the content of total phenolics in fruits. Other parameters such as cultivation conditions, harvest time, ripening stage and environmental factors also influence the antioxidative capacity of plants [32,33].

\section{Antiradical activity}

Antiradical activity of red fruits extracts was measured using four test assays, i.e., DPPH, ABTS, ORAC and PCL, and the antioxidative efficiency (AE) was also assessed. The results obtained are presented in Table 2. The highest antioxidative activity (AA) of the fruit extracts in the presence of DPPH radical was observed in the blackberry, strawberry and raspberry extracts, whereas the lowest activity was noted in the pomegranate and cranberry extracts. AE was also assessed. 
The results showed that the AE of the fruit extracts is variable. Despite the fact that the AA of the pomegranate extract was significantly lower $(\mathrm{P}<0.05)$ than those of the blackberry and strawberry extracts, the $\mathrm{TEC}_{50}$ at medium concentration $\left(\mathrm{EC}_{50}\right)$ was the shortest time to reach the plateau phase. The other samples were significantly less efficient $(\mathrm{P}<0.05)$. The results enabled classification of $\mathrm{AE}$ of the fruit extracts in the following order: pomegranate $>$ strawberry $>$ blackberry $>$ cranberry $>$ raspberry.

The pomegranate extract exhibited the highest antioxidative activity (AA) in the presence of the ABTS cationradical. The activity of other fruit extracts was about $65 \%$ lower (Table 2). Despite this superiority, pomegranate fruit extract recorded the lowest AE comparatively to blackberry and cranberry, and the longest $\mathrm{TEC}_{50}(19.11 \mathrm{~min})$ to reach the plateau phase of $\mathrm{EC}_{50}(910.02 \mathrm{ppm})$. The other samples were significantly more efficient $(\mathrm{P}<0.05)$. The results enabled classification of $\mathrm{AE}$ of the fruit extracts in the following order: blackberry $>$ cranberry $>$ raspberry $>$ strawberry $>$ pomegranate.

Photochemiluminescence assay (PCL) enabled measurement of the superoxide anion-radical scavenging activity in the fruit extracts (Table 2). PCL assay reflects the capacity of water-soluble (ACW) and lipid-soluble components (ACL). Among all the fruit extracts the cranberry and blackberry extracts were characterised by the highest ACW (1.41 and $1.28 \mu \mathrm{mol}$ Trolox/g), while the pomegranate extract had the lowest ACW value $(0.07 \mu \mathrm{mol}$ Trolox/g). The results of the ACL evaluation showed that the strawberry extract was less effective than other fruit extracts, as its activity was about $57 \%$ lower. The total ACL activity of all the extracts was greater than the activity of the ACW fraction. The IAC value, as the total activity of both fractions, showed that the superoxide anion-radical activity was the highest in the cranberry, blackberry and raspberry extracts. The other extracts exhibited significantly lower antiradical activity $(\mathrm{P}<0.05)$.

As can be seen from Table 2, the blackberry extract exhibited the lowest activity which was two times lower than that of blackberry extract recording the highest potential $(3874 \mu \mathrm{mol}$ Trolox/g). The peroxyl radical scavenging activity of the fruit extracts was ranked in the descending order as follows: blackberry $>$ cranberry $>$ raspberry $>$ pomegranate $>$ strawberry. The results indicated also that $\mathrm{ORAC}_{\mathrm{FL}}$ values were significantly higher in dark red fruits $(\mathrm{P}<0.05)$.
Table 2 Antioxidant activity of fruit extracts determined by five different assays

\begin{tabular}{|c|c|c|c|c|c|}
\hline \multirow[t]{2}{*}{ Assay } & \multicolumn{5}{|l|}{ Extract } \\
\hline & Strawberry & Raspberry & Blackberry & Cranberry & Pomegranate \\
\hline \multicolumn{6}{|c|}{ AA (mg Tx/g dw) } \\
\hline DPPH & $0.336^{\mathrm{cd}} \pm 0.028$ & $0.294^{\mathrm{c}} \pm 0.021$ & $0.351^{\mathrm{d}} \pm 0.027$ & $0.142^{\mathrm{a}} \pm 0.011$ & $0.179^{b} \pm 0.006$ \\
\hline ABTS & $0.297^{b} \pm 0.018$ & $0.255^{\mathrm{ab}} \pm 0.019$ & $0.291^{\mathrm{b}} \pm 0.012$ & $0.203^{\mathrm{a}} \pm 0.015$ & $0.761^{c} \pm 0.051$ \\
\hline \multicolumn{6}{|l|}{$\mathrm{EC}_{50}(\mathrm{ppm})$} \\
\hline DPPH & 3.77 & 4.10 & 3.66 & 9.40 & 5.00 \\
\hline ABTS & 21.79 & 35.83 & 25.64 & 74.84 & 910.02 \\
\hline \multicolumn{6}{|l|}{$\mathrm{T}_{\mathrm{EC} 50}(\min )$} \\
\hline DPPH & 45.36 & 66.33 & 50.95 & 28.63 & 5.68 \\
\hline ABTS & 14.85 & 5.99 & 3.47 & 1.64 & 19.11 \\
\hline \multicolumn{6}{|l|}{$\mathrm{AE}\left(\times 10^{-3}\right)$} \\
\hline DPPH & 5.81 & 3.67 & 5.40 & 3.71 & 37.89 \\
\hline ABTS & 3.10 & 4.71 & 11.22 & 8.21 & 0.06 \\
\hline \multicolumn{6}{|l|}{ Classification } \\
\hline DPPH & High & Medium & High & Medium & Very high \\
\hline ABTS & Medium & Medium & Very high & High & Low \\
\hline \multicolumn{6}{|c|}{ PCL $(\mu \mathrm{mol} \mathrm{Tx} / \mathrm{mg})$} \\
\hline ACW & $0.82^{b} \pm 0.19$ & $0.97^{b} \pm 0.17$ & $1.28^{b c} \pm 0.21$ & $1.41^{\mathrm{c}} \pm 0.17$ & $0.07^{\mathrm{a}} \pm 0.02$ \\
\hline ACL & $1.14^{\mathrm{a}} \pm 0.19$ & $2.53^{\mathrm{b}} \pm 0.28$ & $2.61^{\mathrm{b}} \pm 0.35$ & $2.82^{\mathrm{b}} \pm 0.41$ & $2.76^{\mathrm{b}} \pm 0.31$ \\
\hline IAC & $1.96^{\mathrm{a}} \pm 0.38$ & $3.50^{\mathrm{ab}} \pm 0.45$ & $3.89^{\mathrm{b}} \pm 0.56$ & $4.23^{\mathrm{b}} \pm 0.58$ & $2.83^{\mathrm{a}} \pm 0.33$ \\
\hline $\begin{array}{l}\mathrm{ORAC}_{\mathrm{FL}} \\
(\mu \mathrm{mol} \mathrm{Tx} / \mathrm{g})\end{array}$ & $2105^{\mathrm{a}} \pm 196$ & $2511^{\mathrm{ab}} \pm 178$ & $3874^{\mathrm{c}} \pm 274$ & $2798^{\mathrm{b}} \pm 179$ & $2478^{\mathrm{ab}} \pm 202$ \\
\hline
\end{tabular}

Values are means of three determinations $\pm \mathrm{SD}$

Means in a verse followed by the same letter are not significantly different $(\mathrm{P}<0.05)$

$A A$ antioxidant activity, $E C_{50}$ extract's concentration needed to scavenge $50 \%$ of initial radical content, $T_{\mathrm{EC} 50}$ time needed for radical plateau at $\mathrm{EC}_{50}$ concentration, $A E$ antiradical efficiency, $P C L$ photochemiluminescence assay, $A C W$ water soluble fraction activity, $A C L$ lipid soluble fraction activity, $I A C$ integral antioxidant capacity, $O R A C_{\mathrm{FL}}$ oxygen radical absorbance capacity assay, $T x$ Trolox 
The previous studies on red fruits have been indicated their important antioxidant potencies. The high antioxidative efficiency of strawberry on DPPH [34] and ORAC assays [35] has been reported. The potency of this fruit varies considerably between varieties [34]. Previous researches mentioned the efficacy of antiradical potential of blackberry [35, 36 ] and pointed out its strong correlation to the total amount of phenolic compounds [36]. The greatest antiradical capacities of blackberries than strawberries have been noticed previously [20], our study is not in agreement with this finding and showed similarity between both fruit extracts.

The bioactivity of juices obtained from red fruits has also been examined. Wang and Lin [37] noted the greatest antioxidative capacity (ORAC) of ripe strawberry, blackberry and raspberry juices. In addition, unripe strawberries, blackberries, cranberries and pomegranates juice have been shown to be more effective than juice prepared from the ripe ones [38]. These above findings justify the increasing interest in red fruits due to their double importance as natural sources of antioxidant and valuable food.

Our results revealed considerable variation in the antioxidative activity of the red fruit extracts. It may be attributed to the individual actions of compounds contained in the extracts, mainly phenolic compounds, e.g. ellagic acid and anthocyanins. These compounds may block free radicals and prevent reactions caused by a single active oxygen atom.

Principal component analysis (PCA) was applied to better understand the trends and relationships between the variables of different fruit extracts. The data were analysed by means of PCA to determine the systematic variation and underlying relationships between active compounds in the fruit extracts and antiradical properties (Fig. 1a-c). The PCA results showed noticeable differences between the pomegranate, cranberry, strawberry, raspberry and blackberry extracts. Figure 1a shows the PCA data concerning the content of active compounds in the fruit extracts and their antiradical activity. The first two principal components accounted for $75.46 \%(\mathrm{PC} 1=47.10 \%$ and $\mathrm{PC} 2=28.36 \%)$ of the total variation. The first component was mainly correlated with the PCL test water-soluble fraction (PCL ACW) $(r=0.9328)$ and AE in the ABTS test (ABTS AE) $(r=0.9617)$. It was negatively correlated with the EAD $(r=-0.8664)$ and TA $(r=-0.9651)$. The other principal component was mostly correlated with the content of TPC $(r=0.8463)$ and isoquercitrin derivatives (IQD) $(r=0.7917)$. It was negatively correlated with the PCL test lipid-soluble fraction (PCL ACL) $(r=-0.7401)$. The samples with lower sum of flavonoids (SF) were located under the horizontal axis. The extracts with high PELD and SF content were mostly located above the $\mathrm{x}$ axis. On the right of the score plot, there were samples of the blackberry and cranberry extracts with low TPC content. The strawberry and pomegranate extracts were located on the left of the score plot. They had high EAD content.
Figure $1 \mathrm{~b}$ shows the PCA data concerning the content of active compounds and the antioxidative activity of the fruit extracts. The first two principal components accounted for $73.32 \%(\mathrm{PC} 1=43.41 \%$ and $\mathrm{PC} 2=29.91 \%)$ of the total variation. The first component was mainly correlated with the sum of flavonoids (SF) $(r=0.2293)$, but VC $(r=-0.2404)$ and EAD $(r=-0.2377)$ were negatively correlated. The other principal component was correlated with CYAD $(r=0.2538)$, but it was mostly negatively correlated with the content of TA $(r=0.3465)$ and TPC $(r=-0.2746)$. The samples with the lowest content of TPC were located above the horizontal axis, but the raspberry and strawberry extracts were located below the axis and represented high PELD and $\mathrm{SF}$ content. On the left of the score plot there was the pomegranate sample with high EAD, TA and VC content.

Figure 1c shows the analysis of data concerning the antiradical activity of the fruit extracts. The first two principal components accounted for $91.21 \%$ ( $\mathrm{PC} 1=62.68 \%$ and $\mathrm{PC} 2=28.53 \%$ ) of the total variation. The first component was mainly correlated with the DPPH AE $(r=0.1738)$. It was negatively correlated with ABTS AE $(r=-2575)$ and PCL ACW $(r=-0.2359)$. The other principal component was mainly correlated with the PCL ACL $(r=0.4988)$ and DPPH AE $(r=0.4216)$. The samples with high content of PELD, IQD, SF and TPC were located below the horizontal axis. The extracts with low PELD content, i.e. the cranberry, blackberry and pomegranate extracts, were mostly located above the $\mathrm{x}$ axis. On the right of the score plot there were samples of the strawberry and pomegranate extracts with high EAD and TPC content.

\section{Conclusion}

This study indicated clearly that the red fruits exhibited significant in vitro antioxidative activity against diverse free radicals. The various antioxidative mechanisms of the red fruits may be attributed to their strong hydrogen-donating, metal-chelating capacity and their effectiveness as hydroxyl radical scavengers. The phenolic compounds and anthocyanins appear to be responsible on the antiradical activity, however, their contribution to the overall antioxidant activities is discussable and further researches are necessary to find other possible bioactive components.

The use of natural antioxidants in food is desirable for nutritional reasons: (I) high consumption of phenolic compounds as part of fortified food products, (II) reduction of the negative impact of free radicals on human health and food quality. However, the application of red fruit extracts in the food industry is limited due to the high manufacturing costs and the difficult to guarantee their antioxidant efficiency. Our results provided new and useful information concerning the antiradical properties of red fruits, 


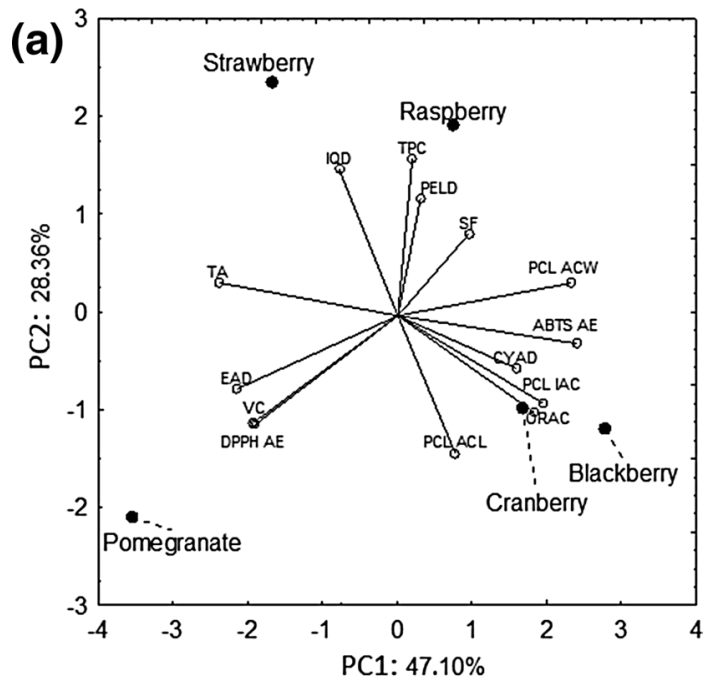

(b)

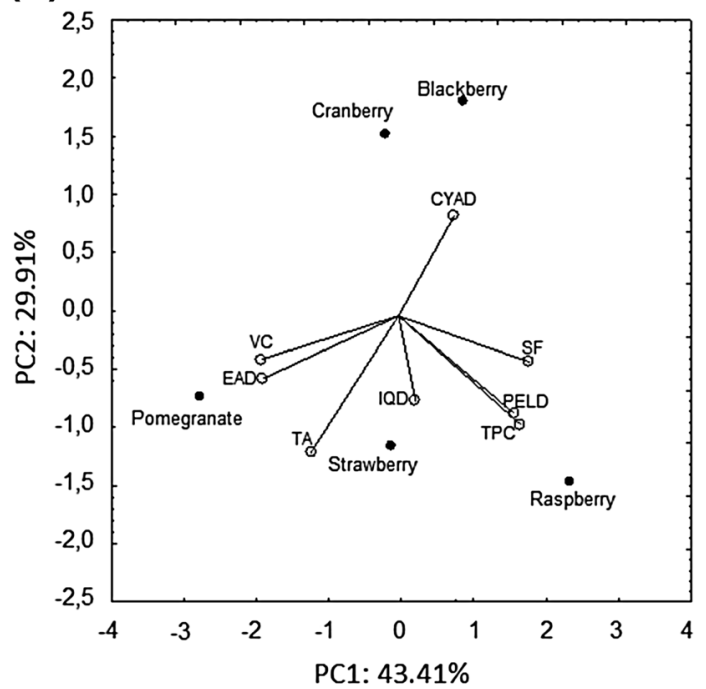

(c)

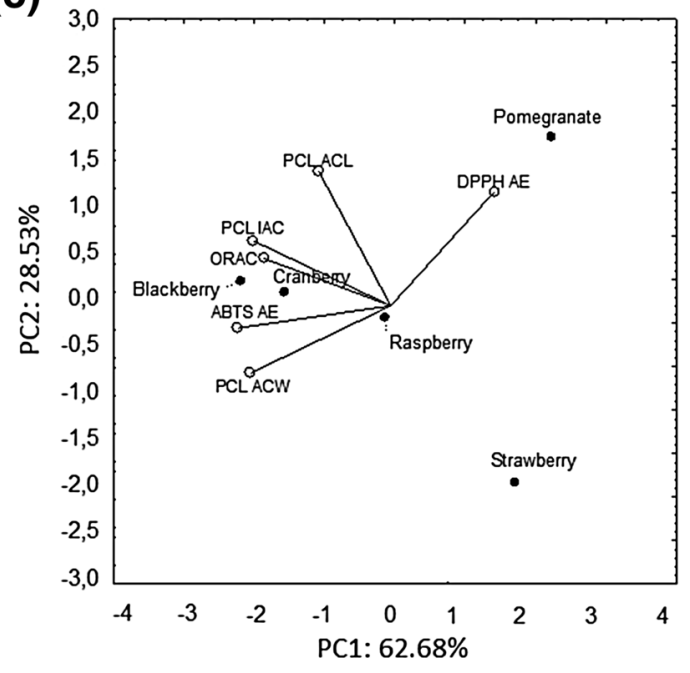

Fig. 1 Principal component analysis (PCA) of the loadings plot and the score plot of data from: a active compounds content, antiradical activity of fruit extracts, $\mathbf{b}$ active compounds content of fruit extracts, c antiradical activity of fruit extracts. $C Y A D$ cyanidin derivatives, $P E L D$ pelargonidin derivatives, $E A D$ ellagic acid derivatives, $I Q D$ isoquercitrin derivatives, $T A$ total anthocyanins, $S F$ flavonoids sum, $T P C$ total phenolic compounds, $V C$ vitamin $\mathrm{C}, P C L A C W$ Photochem test water-soluble fraction, $P C L A C L$ Photochem test lipid-soluble fraction, $P C L I A C$ Photochem test integral antioxidant capacity, ABTS $A E$ antioxidant efficiency in ABTS test, $D P P H A E$ antioxidant efficiency in DPPH test, ORAC oxygen radical antioxidant capacity

which can be applied in the development of functional food with directed health value.

Acknowledgements This work was supported by the National Science Centre of Poland under Grant N N312 374537. The language correction was financed within the framework of Ministry of Science and Higher Education programme as "Regional Initiative Excellence" in years 2019-2022, Project Number 005/RID/2018/19.

\section{Compliance with ethical standards}

Conflict of interest The authors declare no financial and commercial conflicts of interest and that the manuscript does not contain experiments using animals or human studies.

Open Access This article is distributed under the terms of the Creative Commons Attribution 4.0 International License (http://creativeco mmons.org/licenses/by/4.0/), which permits unrestricted use, distribution, and reproduction in any medium, provided you give appropriate credit to the original author(s) and the source, provide a link to the Creative Commons license, and indicate if changes were made.

\section{References}

1. O.T. Kasaikina, D.A. Krugovov, E.A. Mengele, Eur. J. Lipid Sci. Technol. (2017). https://doi.org/10.1002/ejlt.201600286

2. S. Vieira, G.D. Zhang, E.A. Decker, J. Am. Oil Chem. Soc. (2017). https://doi.org/10.1007/s11746-017-2958-2

3. A. Augustyniak, G. Bartosz, A. Cipak, G. Duburs, L. Horakova, W. Łuczaj, M. Majekova, A.D. Odysseos, L. Rackova, E. Skrzydlewska, M. Stefek, M. Strosova, G. Tirzitis, P.R. Venskutonis, J. Viskupicova, P.S. Vraka, N. Zarkovic, Free Rad. Res. 44(10), 1216-1262 (2016). https://doi.org/10.3109/10715762.2010.50849 5

4. F. Shahidi, P. Ambigaipalan, J. Funct. Foods 18(B), 820-897 (2015). https://doi.org/10.1016/j.jff.2015.06.018

5. P.I. Oteiza, C.G. Fraga, D.A. Mills, D.H. Taft, Mol. Aspects Med. 61, 41-49 (2018). https://doi.org/10.1016/j.mam.2018.01.001

6. B. Salehi, M. Martorell, J.L. Arbiser, A. Sureda, N. Martins, P.K. Maurya, M. Sharifi-Rad, P. Kumar, J. Sharifi-Rad. Biomolecules 8, 124 (2018). https://doi.org/10.3390/biom8040124

7. M. Laguerre, C. Bayrasy, A. Panya, J. Weiss, D.J. McClements, J. Lecomte, E.A. Decker, P. Villeneuve, Crit. Rev. Food Sci. Nutr. 55(2), 183-201 (2015). https://doi.org/10.1080/10408 398.2011 .650335

8. D. Xiao, A. Sandhu, Y. Huang, E. Park, I. Edirisinghe, B.M. Burton-Freeman, Food Funct. 8(11), 3970 (2017). https://doi. org/10.1039/C7FO00885F 
9. A. Gramza-Michałowska, A. Sidor, B. Kulczyński, J. Funct. Food. 37, 116-137 (2017). https://doi.org/10.1016/j.jff.2017.07.050

10. R. Amarowicz, Eur. J. Lipid Sci. Technol. 118(5), 677-679 (2016). https://doi.org/10.1002/ejlt.201600077

11. D. Kmiecik, A. Gramza-Michałowska, J. Korczak, Food Chem. 239, 858-864 (2018). https://doi.org/10.1016/j.foodc hem.2017.07.025

12. J. Oszmiański, Acta Sci. Pol. Technol. Aliment. 1(1), 37-45 (2002)

13. PN-A-04019:1998P. Food products. Determination of vitamin C (1998)

14. C. Sánchez-Moreno, J.A. Larrauri, F. Saura-Calixto, J. Sci. Food Agric. 76, 270-276 (1988). https://doi.org/10.1002/(SICI)10970010(199802)76

15. R. Re, N. Pellegrini, A. Proteggente, A. Pannala, M. Yang, C. Rice-Evans, Free Rad. Biol. Med. 26, 1231-1237 (1999)

16. J. Pérez-Jiménez, F. Saura-Calixto, Int. J. Food Sci. Technol. 43(1), 185-191 (2008)

17. A. Gramza-Michałowska, A. Sidor, J. Reguła, B. Kulczyński, Acta Sci. Pol. Technol. Aliment. 14(4), 331-341 (2015). https://doi. org/10.17306/J.AFS.2015.4.33

18. D. Gramza-Michałowska, J. Kmiecik, A. Kobus-Cisowska, K. Żywica, A. Dziedzic, Brzozowska, Pol. J. Food Nutr. Sci. 68(1), 6371 (2018). https://doi.org/10.1515/pjfns-2017-0009

19. N. Ljevar, M. Ćurko, K. Tomasevic, V.G. Radosevic, K.K. Srcek, Ganic, Food Technol. Biotech. 54(2), 145-155 (2016). https://doi. org/10.17113/ftb.54.02.16.4208

20. W. Huang, H. Zhang, W. Liu, C. Li, J. Zhejiang Univ. Sci. B 13(2), 94-102 (2012). https://doi.org/10.1631/jzus.B1100137

21. R. Li, X.G. Chen, K. Jia, Z.P. Liu, H.Y. Peng, Springerplus 5(1), 914 (2016). https://doi.org/10.1186/s40064-016-2639-x

22. S. Mardigal-Carballo, G. Rodriguez, C.G. Krueger, M. Dreher, J.D. Reed, J. Funct. Foods 1(3), 324-329 (2009). https://doi. org/10.1016/j.jff.2009.02.005

23. G. Borges, W. Mullen, A. Crozier, Food Funct. 1(1), 73-83 (2010). https://doi.org/10.1039/c0fo00008f

24. M.H. Grace, A.R. Massey, F. Mbeunkui, G.G. Yousef, M.A. Lila, J. Food Sci. 77(8), 176-183 (2012). https://doi.org/10.111 $1 /$ j.1750-3841.2012.02788.x
25. G. Casedas, F. Les, M.P. Gomez-Serranillos, C. Smith, V. Lopez, Food Funct. 8, 4187-4193 (2017). https://doi.org/10.1039/c7fo0 $1205 \mathrm{e}$

26. S.H. Hakkinen, S.O. Karenlampi, I.M. Heinonen, H.M. Mykkanen, A.R. Torronen, J. Agric. Food Chem. 47(6), 2274 2279 (1999)

27. M. Gundogdu, Y. Kan, I. Canan, Turk. J. Agric. For. 40(3), 344351 (2016). https://doi.org/10.3906/tar-1511-78

28. M. Tosun, S. Ercisli, H. Karlidag, M. Sengul, J. Food Sci. 74(7), 575-579 (2009). https://doi.org/10.1111/j.1750-3841.2009.01297 . $\mathrm{x}$

29. A. Anahita, R. Asmar, O. Fauziah, Int. Food Res. J. 22(3), 1212$1217(2015)$

30. R. Amarowicz, F. Shahidi, J. Funct. Foods 38(B), 656-662 (2017). https://doi.org/10.1016/j.jff.2017.04.002

31. K. Gündüz, E. Ozdemir, Food Chem. 155, 298-303 (2014). https ://doi.org/10.1016/j.foodchem.2014.01.064

32. J. Pincemail, C. Kevers, J. Tabart, J.O. Defraigne, J. Dommes, J. Food Sci. 77(2), C205-C210 (2012). https://doi.org/10.111 $1 / \mathrm{j} .1750-3841.2011 .02539 . \mathrm{x}$

33. L. Jaakola, Trends Plant Sci. 18(9), 477-483 (2013). https://doi. org/10.1016/j.tplants.2013.06.003

34. H. Kelebek, S. Selli, J. Liq. Chromatrogr. Related Technol. 34(20), 2495-2504 (2011)

35. A. Floegel, D.O. Kim, S.J. Chung, S.I. Koo, O.K. Chun, J. Food Comp. Anal. 24(7), 1043-1084 (2011). https://doi.org/10.1016/j. jfca.2011.01.008

36. E. Sariburun, S. Şahin, C. Demir, C. Türkben, V. Uylaşer, J. Food Sci. 75(4), 328-335 (2010). https://doi.org/10.111 1/j.1750-3841.2010.01571.x

37. S.Y. Wang, H.S. Lin, J. Agric. Food Chem. 40, 140-146 (2000). https://doi.org/10.1021/jf9908345

38. N.P. Seeram, M. Aviram, Y. Zhang, M. Henning, L. Feng, M. Dreher, D. Heber, J. Agric. Food Chem. 56, 1415-1422 (2008). https://doi.org/10.1021/jf073035s

Publisher's Note Springer Nature remains neutral with regard to jurisdictional claims in published maps and institutional affiliations. 